\title{
Análise da pesquisa em HQs no Brasil: a contribuição da ECA- USP
}

\author{
Paulo Vitor Martins Albuquerque \\ Universidade Federal do ABC, Santo André, SP, Brasil \\ https://orcid.org/0000-0002-4171-462X
}

Maria Gabriela Silva Martins da Cunha Marinho

Universidade Federal do ABC, Santo André, SP, Brasil

https://orcid.org/0000-0002-5698-0437

\section{João Elias Nery}

Faculdade Paulus de Tecnologia e Comunicação, São Paulo, SP, Brasil https://orcid.org/0000-0003-0636-4879

\section{Resumo}

Este artigo busca levantar um histórico da pesquisa sobre histórias em quadrinhos no Brasil, especialmente no âmbito da Escola de Comunicações e Artes da Universidade de São Paulo, apontando autores e iniciativas de relevância. Utilizou-se a metodologia da revisão de literatura aliada à pesquisa bibliográfica. Foi descrita uma possível trajetória da pesquisa brasileira em quadrinhos, dentro dos limites propostos, desde seus primórdios até os dias atuais. Constatou-se a inicial resistência por parte das elites culturais e dos pares acadêmicos, seguida pela progressiva aceitação do campo de investigação à medida que os trabalhos foram aumentando em número e ganhando publicidade. Procurou-se indicar perspectivas e limites vislumbrados pelos pesquisadores da área. Ao final, elencou-se uma relação de espaços de pesquisa mapeados em território nacional. Conclui-se que a área teve clara expansão, evidenciando-se, no entanto, a necessidade de contínuo incremento das oportunidades de estudo, como, por exemplo, por meio da abertura de programas de pós-graduação, como mestrado e doutorado específicos.

\section{Palavras-chave}

História em quadrinhos; Comunicação; Pesquisa; Escola de Comunicações e Artes; Universidade de São Paulo 


\section{Introdução}

As histórias em quadrinhos, cada vez mais difundidas em nossos dias, nem sempre desfrutaram de prestígio e validação, especialmente por parte das camadas mais elitizadas da sociedade. Vistos com desconfiança no passado, os quadrinhos enfrentaram um longo caminho pelos séculos XIX e XX até, pouco a pouco, se firmarem como linguagem referendada tanto no senso comum, quanto nos espaços intelectuais. A trajetória não foi diferente em relação ao estudo acadêmico sobre os quadrinhos - especificamente no Brasil, objeto deste artigo, para o qual tentaremos traçar um breve histórico, elencando uma série de acontecimentos e pesquisadores, sobretudo no que se refere às iniciativas engendradas em torno da Escola de Comunicações e Artes da Universidade de São Paulo, a ECA-USP, por meio de suas fontes de registro documental. Este artigo pretende, portanto, tematizar a incorporação dos quadrinhos como objeto de pesquisa acadêmica. Há poucos artigos e registros em livro dando conta do histórico da pesquisa em quadrinhos no Brasil, especialmente relacionados à experiência em torno da ECA-USP. Iniciativas como a de Vergueiro (2017a, 2017b), Vergueiro et al. (2013) e Vergueiro e Santos (2014) contribuem para o levantamento desta memória. 0 recorte apresentado seleciona e delimita um escopo específico. Portanto, não tem caráter exaustivo e deixa de contemplar iniciativas cuja relevância exige uma abordagem aprofundada que extrapolaria os limites desse artigo.

\section{Metodologia}

Foi utilizada como metodologia a revisão de literatura, aliada a uma pesquisa de caráter bibliográfico. A primeira abordagem pretende identificar e analisar a trajetória de estudos acadêmicos sobre quadrinhos, concentrando-se inicialmente na ECA-USP. Para tanto, procede com a coleta de dados bibliográficos, identificando acervos, tomando depoimentos para cotejar e sistematizar as informações de modo a estabelecer uma trajetória de pesquisa e de pesquisadores. Tal sistematização apresenta, também, uma diacronia, com o objetivo de fornecer elementos que contribuam para a pesquisa na área. A pesquisa de caráter bibliográfico, para Gil (2002, p. 44) é aquela "desenvolvida com base em material já elaborado, constituído principalmente de livros e artigos científicos". Gil (2002, p. 45) ainda argumenta que a principal vantagem do uso desse tipo de pesquisa é "permitir ao investigador a cobertura de uma gama de fenômenos muito mais ampla do que aquela 
que poderia pesquisar diretamente". Vantagem que aumenta "quando o problema de pesquisa requer dados muito dispersos pelo espaço" (GIL, 2002, p. 45). Por fim, segundo Gil (2002, p. 45), tal pesquisa bibliográfica "é indispensável nos estudos históricos [...], [quando] não há outra maneira de conhecer os fatos passados se não com base em dados bibliográficos".

\section{A pesquisa em HQ: da desconfiança à legitimação}

Ao longo do século XX, os quadrinhos foram desmerecidos por muitos setores da sociedade, incluindo a academia e os intelectuais. As obras foram deslegitimadas e até mesmo perseguidas de uma maneira que não ocorreu com outras manifestações artísticas. Tal rejeição ocorreu em todo o mundo, incluindo o Brasil. Havia um imaginário negativo préconcebido em relação ao gênero.

0 ápice deste preconceito pode ser verificado em iniciativas como a obra Seduction of the innocent (1954) ${ }^{1}$, do psiquiatra alemão Fredric Wertham, da qual falaremos mais adiante (VERGUEIRO et al., 2013).

Nas universidades, os quadrinhos eram vistos com pouca seriedade, o que desencorajava as pesquisas. 0 gênero sofreu durante décadas a indiferença da alta intelectualidade, motivada talvez por sua natureza híbrida entre linguagem escrita e imagem desenhada, além de ser um veículo comumente popular. Uma crescente aceitação pela sociedade, contudo, fez com que se começasse a vê-los de outra forma. Não por acaso, as pesquisas sobre o assunto têm crescido bastante no Brasil. Hoje, há cada vez mais professores universitários interessados no tema e há um cada vez maior número de trabalhos relacionados (VERGUEIRO, 2017a).

\subsection{A pesquisa em quadrinhos no mundo}

As primeiras investigações sobre os quadrinhos remontam aos anos 1940, época em que o gênero desfrutava de grande popularidade em países como os EUA e o Brasil. A partir deste período, estudiosos interessados nos efeitos das mídias de massa sobre o público elaboraram teorias de orientação Funcionalista a respeito do tema. "Um exemplo é o

1 WERTHAM, Fredric. Seduction of the innocent. New York: Rinehart \& Company, 1954. Apud Vergueiro et al. (2013). 
trabalho de Bogart (1973:224), realizado no início da década de 1950, que colheu opiniões de mais de uma centena de leitores do jornal tabloide News, de Nova Iorque, e analisou as tiras nele publicadas" (VERGUEIRO; SANTOS, 2014, p. 4366).

Ao longo do tempo, houve estudos sobre os quadrinhos sob diversos enfoques: Funcionalistas, Marxistas ou críticos, dos Estudos Culturais e da Semiologia Estruturalista são alguns exemplos.

Enquanto estudiosos Funcionalistas não viam nos quadrinhos uma leitura ameaçadora, alguns autores criticavam fortemente a linguagem. Um exemplo desta perspectiva é o psiquiatra alemão radicado nos Estados Unidos Fredric Wertham, que publicou, em 1954, o livro Seduction of the innocent, ligando os quadrinhos à criminalidade entre os jovens.

Uma referência de estudos sobre quadrinhos de abordagem Marxista ou crítica provém do Chile, onde os teóricos Dorfman e Mattelart editaram a obra Para leer al Pato Donald $(1971)^{2}$, em que os quadrinhos e outros produtos de massa eram acusados de disseminar o capitalismo e o american way of life. Ainda no Chile, Dorfman e Jofré, em Superman y sus amigos del alma (1974)3), editado no Brasil como Super-homem e seus amigos do peito (Paz e Terra, 1978), analisaram a ideologia dos quadrinhos de super-heróis, atribuindo-lhes a defesa da ideologia burguesa (VERGUEIRO; SANTOS, 2014).

É importante esclarecer, entretanto, que a linha de pensamento da teoria crítica não se volta especificamente ao estudo dos quadrinhos. Pode, sim, eventualmente, ser aplicada a esse campo, tratando-o como parte da indústria cultural. A obra de Dorfman e Mattelart, por exemplo, foi importante referência para a interpretação do "Imperialismo cultural". A crítica feita por estes autores denunciava o uso dos quadrinhos em favor das ideologias norteamericanas. Necessário assinalar ainda que tal interpretação difere das argumentações de um autor como Wertham, que, diferentemente de uma análise política, buscava censurar e, em última instância, até mesmo proibir a publicação de revistas em quadrinhos.

Nos anos 1960, os Estruturalistas europeus foram os primeiros a identificar nos quadrinhos uma organização distinta de outras formas de narrativas e o uso de elementos

\footnotetext{
2 DORFMAN, Ariel; MATTELART, Armand. Para leer al pato Donald. Valparaíso: Ediciones Universitarias de Valparaíso, 1971. Apud Vergueiro; Santos (2014).

3 DORFMAN, Ariel; JOFRÉ, Manuel. Superman y sus amigos del alma. Buenos Aires: Editorial Galerna, 1974. Apud Vergueiro; Santos (2014).
} 
particulares que geram conexões entre imagem e texto das páginas para se alcançar um sentido (VERGUEIRO; SANTOS, 2014).

A partir desta perspectiva, entre os pioneiros a reconhecer o valor dos quadrinhos estavam Umberto Eco e Marshall McLuhan, um italiano e um canadense, respectivamente (VERGUEIRO et al., 2013). McLuhan "[...] formulou uma teoria da comunicação baseada no relacionamento entre os seres humanos e as mídias. Para ele, os meios são extensões do corpo humano e atuam sobre um ou mais sentidos [...] (VERGUEIRO; SANTOS, 2014, p. 4368). Ainda para Vergueiro e Santos (2014, p. 4369), "ao desnudar os mecanismos da linguagem dos quadrinhos, Eco possibilitou a compreensão mais ampla de seu potencial narrativo e estético, abrindo caminho para outros pesquisadores [...]".

Umberto Eco, a propósito, visitou a cidade de São Paulo no ano de 1966, quando tinha 34 anos. Na ocasião, manteve contato com a Universidade de São Paulo e ministrou um curso de 15 dias sobre cultura de massas na Universidade Presbiteriana Mackenzie. Por aquela época, o autor problematizava questões como as histórias em quadrinhos em seu livro Apocalípticos e integrados 4 . Sua visita ao Brasil também tinha como objetivo apoiar a legitimação dos quadrinhos como manifestação artística válida (VERGUEIRO et al., 2013).

\subsection{A pesquisa em quadrinhos no Brasil}

0 estudo sobre quadrinhos no Brasil remonta a quase 50 anos, apesar de nem sempre difundido (VERGUEIRO; SANTOS, 2014), já que estudar histórias em quadrinhos era algo pouco louvável para a academia nos anos 1960. Entre os pioneiros, estão nomes como Álvaro de Moya, José Marques de Melo, Moacy Cirne, Francisco Araújo, Sonia Maria Bibe Luyten, Antonio Luiz Cagnin e Waldomiro de Castro Santos Vergueiro, pesquisadores que sofreram relativa rejeição ao tema no ambiente acadêmico (VERGUEIRO et al., 2013).

Uma vez que os quadrinhos, como entendidos hoje, tiveram como primeiro meio de veiculação os jornais impressos, boa parte dos estudos relacionados ao tema se deram a partir do prisma das Ciências da Comunicação (VERGUEIRO, 2017a), como se pode exemplificar pelo caso da ECA-USP, que será mais detidamente abordado neste artigo. É possível afirmar ainda que as principais correntes teóricas da Comunicação - entre elas Funcionalismo, Marxismo, Midiologia, Estruturalismo e Estudos Culturais - serviram de

4 ECO, Umberto. Apocalípticos e integrados. São Paulo: Perspectiva, 1979. Apud Vergueiro et al. (2013). 
base para os estudos dos investigadores brasileiros sobre quadrinhos, como veremos a seguir (VERGUEIRO; SANTOS, 2014).

\subsection{Um histórico da pesquisa em quadrinhos no Brasil, com ênfase na ECA- USP}

Como a trajetória da pesquisa sobre quadrinhos no Brasil já passa de meio século, pode-se dizer que um primeiro tratamento acadêmico aos quadrinhos proveio de aficionados do tema, aliados a alguns desenhistas. Foi realizada em São Paulo, em 1951, a Primeira Exposição Internacional de Histórias em Quadrinhos, promovida por um grupo de jovens estudiosos, como Álvaro de Moya, Reynaldo de Oliveira, Syllas Roberg, Miguel Penteado e Jayme Cortez (VERGUEIRO, 2017a), todos já falecidos.

Mais especialmente, foi Álvaro de Moya quem, em 18 de junho de 1951, coordenou a referida exposição de quadrinhos, talvez uma das pioneiras no mundo e provavelmente a primeira no Brasil. Para esta Primeira Exposição Internacional de Histórias em Quadrinhos, alguns desenhos originais americanos foram oferecidos ao MASP para exibição, sendo, no entanto, recusados. A exposição foi realizada, então, em um espaço chamado Centro Cultura e Progresso (VERGUEIRO et al., 2013). A iniciativa teve acentuado sucesso, o que motivou reportagens de TV e jornal. Naqueles dias, os quadrinhos estavam sob ataque nos EUA, onde eram considerados prejudiciais, graças a estudos como os de Fredric Wertham. No Brasil, não era diferente. A própria exposição chegou a ser alvo de desconfiança (VERGUEIRO et al., 2013).

Tratou-se da primeira empreitada a conceder aos quadrinhos uma abordagem científica, buscando auxílio de teorias utilizadas para o cinema, além de apontar particularidades dos quadrinhos brasileiros. Dos estudiosos envolvidos com a exposição de 1951, apenas Álvaro de Moya seguiu com a carreira de docente universitário, sendo professor colaborador na ECA-USP de 1970 a 1991 (VERGUEIRO, 2017a). Além disso, ainda ministrou a disciplina Quadrinhologia no curso de Editoração e Multimídia da UniFIAM (VERGUEIRO et al., 2013).

Moya também participou da organização do Primeiro Congresso Internacional de Quadrinhos, promovido pela Escola Panamericana de Arte, em conjunto com a Prefeitura de São Paulo e ocorrido em novembro de 1970 - desta vez, sim, no MASP. 0 evento trazia 
exposições com originais e palestras de desenhistas nacionais e estrangeiros (FOGEL, 2019). Moya realizou ainda diversos trabalhos independentes de pesquisa sobre o tema. Em 1970, publicou o livro Shazam! , pela editora Perspectiva, tratando-se da primeira antologia de textos críticos sobre quadrinhos no Brasil. Neste livro, entre outros textos de diversos autores, Moya escreveu um primeiro relato histórico dos quadrinhos no país, mencionando seus principais autores e editores (VERGUEIRO, 2017a).

No ambiente acadêmico, o estudo de quadrinhos principiou no Brasil por volta de 1967 (VERGUEIRO, 2017a), quando José Marques de Melo fundou o Centro de Pesquisas da Comunicação Social, na Faculdade Casper Líbero, em São Paulo. Num grupo de estudos deste centro, foi inventariado o conteúdo dos gibis brasileiros, com o resultado tendo sido publicado no livro Comunicação Social: teoria e pesquisa ${ }^{6}$, de 1970 (VERGUEIRO et al., 2013). A pesquisa seguia a linha dos Estudos de Comunicação e foi feita por um grupo de estudantes de graduação. Coordenada por Melo, foi talvez a primeira investigação brasileira sobre o tema (VERGUEIRO, 2017a).

Melo também ajudou a formular a grade curricular dos cursos de Jornalismo e Editoração da ECA-USP, em cujos planos incluiu uma disciplina sobre história em quadrinhos, pensando na formação interdisciplinar dos alunos. A ECA, por sinal, viria a se destacar por abrigar diversas pesquisas se ocupando das manifestações da cultura de massa. Melo tornou-se diretor da própria ECA-USP entre o fim dos anos 1980 e início dos 1990 (VERGUEIRO, 2017b). Ao ser eleito diretor, instituiu um grupo permanente de pesquisa, o Núcleo de Pesquisa em História em Quadrinhos.

Nos anos 1970, pode-se destacar ainda o trabalho de Moacy Cirne, docente do Departamento de Comunicação Social da Universidade Federal Fluminense, que participou da Revista de Cultura Vozes, onde editou fascículos sobre os quadrinhos. Cirne propunha uma interpretação crítica dos quadrinhos marcada pela orientação Marxista, alinhada com a Escola de Frankfurt. De sua obra, destaca-se o livro Uma introdução política aos quadrinhos ${ }^{7}$, de 1982, reunindo textos marcadamente críticos. Por essa época, fazia muito sucesso o livro Para leer al Pato Donald ${ }^{8}$, de Ariel Dorfman e Armand Mattelart, com críticas aos quadrinhos

\footnotetext{
5 MOYA, Álvaro de. Shazam!. São Paulo: Perspectiva, 1977. Apud Vergueiro (2017a).

6 MELO, José Marques de. Comunicação Social: teoria e pesquisa. Petrópolis: Vozes, 1970. Apud Vergueiro et al. (2013).

7 CYRNE, Moacy. Uma introdução política aos quadrinhos. Rio de Janeiro: Achiamé, 1982. Apud Vergueiro (2017a).

8 DORFMAN, Ariel; MATTELART, Armand. Para leer al pato Donald. Valparaíso: Ediciones Universitarias de Valparaíso, 1971. Apud Vergueiro (2017a).
} 
americanos como veiculadores do modo de vida daquele país (VERGUEIRO, 2017a), como assinalado anteriormente.

A década de 1970 presenciou o florescimento dos estudos sobre quadrinhos nas Ciências da Comunicação no Brasil. Foram criadas duas disciplinas de graduação sobre o tema, tornando o país um dos primeiros a introduzir uma disciplina do gênero em um curso universitário. A primeira experiência ocorreu na Universidade de Brasília, UnB, por volta de 1970, com Francisco Araújo. A iniciativa, no entanto, durou pouco tempo (VERGUEIRO, 2017a). Araújo criou ainda, pela mesma época, a Organização de Professores de Quadrinhos (VERGUEIRO et al., 2013).

A segunda empreitada deu-se na ECA-USP em 1972. A disciplina, chamada Editoração de Histórias em Quadrinhos, foi, inicialmente, ministrada por Sonia Luyten, com apoio de José Marques de Melo, naquele momento chefe do Departamento de Jornalismo e Editoração da ECA (VERGUEIRO, 2017a). Pioneira no Brasil como parte da grade fixa de um currículo acadêmico, a disciplina existe até hoje. A proposta do curso era formar editores de quadrinhos, oferecer uma base teórica para os desenhistas e pesquisadores (VERGUEIRO et al., 2013). Paralelamente, estudantes criaram grupos de estudo e de criação artística, especialmente na Faculdade de Arquitetura e Urbanismo da USP, a FAU-USP, e na ECA-USP, onde produziram fanzines como a revista Balão (VERGUEIRO, 2017a), fundada por Laerte e Luis Gê, que propunha uma linha de crítica social e política. Balão tinha espaço aberto para desenhistas, servindo de laboratório de estilos e roteiros. Contribuíram com a revista nomes como os mencionados Laerte e Luis Gê, além de Paulo e Chico Caruso, Xalberto, Angeli e Glauco (VERGUEIRO et al., 2013).

Sonia Maria Bibe Luyten foi outra pesquisadora com produção inicial de orientação crítica. Esteve à frente da disciplina de graduação intitulada Editoração de Histórias em Quadrinhos, na ECA-USP, além de posteriormente desenvolver uma pesquisa sobre o gênero dos mangás, incluindo os nacionais. Luyten teve intensa atividade acadêmica, chegando a constituir, em 1972, a primeira gibiteca universitária do Brasil, na ECA-USP. 0 chamado Núcleo de Documentação de Histórias em Quadrinhos da ECA-USP foi o primeiro acervo de quadrinhos numa universidade brasileira, com conteúdo obtido a partir das obras de um colecionador (VERGUEIRO, 2017a). Seu surgimento se deu quando José Marques de Melo reuniu um acervo de quadrinhos por meio de uma doação. Nesse acervo, Luyten atuou na área da conservação, enquanto sua organização e sua sistematização ficaram a cargo de 
Antonio Cagnin, com ajuda de Waldomiro Vergueiro. Luyten foi responsável durante muitos anos pelo setor de quadrinhos desta doação, que continha também jornais. Hoje, graças a esta e outras iniciativas, há diversas gibitecas pelo Brasil (VERGUEIRO et al., 2013). Ainda nos anos 1970, durante a ditadura militar, o arquivo do Museu da Imprensa da ECA-USP foi apreendido e queimado, tendo restado apenas o acervo de quadrinhos e de cordel, considerados inofensivos (VERGUEIRO et al., 2013).

Além do trabalho citado, Luyten fundou o primeiro núcleo de pesquisa sobre mangá no Brasil, onde organizou uma mangateca - provavelmente a primeira biblioteca de mangás do país. Da disciplina de histórias em quadrinhos que ministrava, surgiu ainda um núcleo de pesquisas sobre mangá (VERGUEIRO, 2017a).

A disciplina pela qual Luyten foi responsável gerou, entre outros frutos, a revista Quadreca, mistura de Quadrinhos + ECA, que divulgava novos desenhistas, dava formação a editores e discutia pesquisa. A pesquisadora ainda ministrou a primeira matéria de Pósgraduação sobre Histórias em Quadrinhos na ECA-USP, em 1983. Desta disciplina, surgiu o livro Histórias em quadrinhos e leitura crítica ${ }^{9}$, com o resultado produzido pelos alunos e por Luyten. Em seguida, vieram outras publicações com a produção de grupos de pesquisa em quadrinhos. Devido a compromissos acadêmicos, Luyten afastou-se por cerca de 14 anos, indo viver no exterior, mais precisamente no Japão. A disciplina de quadrinhos na graduação da ECA ficou então a cargo de Antonio Luiz Cagnin e, em seguida, de Waldomiro Vergueiro, mantendo sempre a formação de editores e pesquisadores. Hoje, o Observatório de Histórias em Quadrinhos da USP, do qual falaremos mais adiante, divulga a produção acadêmica na área (VERGUEIRO et al., 2013).

Paralelamente a uma análise crítica dos quadrinhos, ocorreu no Brasil uma análise Estruturalista, notadamente com o autor Antonio Luiz Cagnin, do qual se destaca a obra Os quadrinhos, de 1975, referência para a análise de quadrinhos do ponto de vista da estrutura narrativa ou dos elementos constitutivos de sua linguagem. Foram influenciados por Cagnin pesquisadores como Orlando Miranda e Roberto Elísio dos Santos. Cagnin foi professor de Semiologia da Imagem na ECA-USP, onde se dedicou por muito tempo à pesquisa dos primeiros autores de quadrinhos do país, em especial o desenhista Angelo Agostini (VERGUEIRO, 2017a).

BIBE LUYTEN, Sonia M. (org.). Histórias em Quadrinhos - leitura crítica. São Paulo: UCBC Paulinas, 1984. Apud Vergueiro et al. (2013). 
Cagnin tentou levantar a história de vida de Angelo Agostini, sem grande sucesso, devido à escassez de documentos. 0 pesquisador, que estudou na França, salienta o alto grau de preservação documental naquele país, em oposição ao cuidado dispensado com a memória no Brasil (VERGUEIRO et al., 2013).

Nos anos 1970, Cagnin participou do Congresso Internacional de Quadrinhos, realizado em São Paulo, sob organização de Álvaro de Moya. 0 pesquisador também assumiu a disciplina de Editoração de Quadrinhos, criada por Sonia Luyten, quando ingressou na USP como professor de Semiologia da Imagem na ECA, empreendendo esforços para incrementar o projeto. Cagnin, aliás, foi quem conseguiu tornar a disciplina obrigatória no curso de Jornalismo da ECA-USP. Foi também o responsável pela iniciativa de recuperação e preservação do acervo do suplemento A Gazetinha, surgido em 1929 no jornal A Gazeta, cujo trabalho de restauração foi feito na Biblioteca Nacional. Além disso, ainda retomou a revista Quadreca, fundada por Sonia Luyten, mas paralisada quando ela foi viver no Japão (VERGUEIRO et al., 2013).

Cagnin foi também docente da Pós-Graduação em Ciências da Comunicação da ECAUSP, onde orientou muitas pesquisas de pós-graduação em quadrinhos (VERGUEIRO, 2017a). Por fim, ainda participou, em 1990, da formação do Centro de Estudos das Histórias em Quadrinhos, que depois se tornou o Núcleo de Estudos das Histórias em Quadrinhos, hoje Observatório de Histórias em Quadrinhos (VERGUEIRO et al., 2013).

Outro nome importante da pesquisa em quadrinhos no Brasil é o já mencionado Waldomiro Vergueiro, que atua na ECA-USP desde 1980 (VERGUEIRO, 2017a).

Durante sua docência na USP, Vergueiro atuou paralelamente nas áreas de Biblioteconomia e de estudo de quadrinhos. No início da carreira, enfatizou a Biblioteconomia. Depois, porém, promoveu a aproximação das duas áreas, Biblioteconomia e quadrinhos. Desenvolveu trabalhos sobre o gênero como fonte de informação, e posteriormente sobre a temática dos quadrinhos na educação. Passou ainda a escrever sobre gibitecas, colaborando para a criação da gibiteca Henfil, em São Paulo, no final dos anos 1980. Ainda nesta época, começou a escrever artigos sobre quadrinhos em veículos da mídia impressa. 0 pesquisador se tornou então uma referência no assunto para os meios de comunicação, sendo requisitado para várias participações (VERGUEIRO, 2017b).

Em 1989, Vergueiro começou a trabalhar conjuntamente com Álvaro de Moya e Luiz Cagnin na ECA-USP, onde os três eram docentes. Naquele mesmo ano, foi criada a Comissão 
de Eventos sobre Histórias em Quadrinhos, por iniciativa de José Marques de Melo. A Comissão reunia Vergueiro, como coordenador, além de Moya e Cagnin, como membros (VERGUEIRO, 2017b). Juntos, fizeram duas atividades: uma mostra sobre o personagem Batman e outra sobre quadrinhos brasileiros (VERGUEIRO, 2017b). Em 1989, por ocasião dos 50 anos de lançamento do personagem do "homem-morcego" , os pesquisadores organizaram a Semana Batman na ECA-USP, promovendo conferências, debates, exibições de cinema, exposições, grafites e homenagens aos editores do herói no Brasil, atraindo mais de 300 visitantes por dia e obtendo grande repercussão na mídia, o que fez do evento o mais difundido da ECA em 1989. Ainda no mesmo ano, promoveram a Semana do Quadrinho Brasileiro, de repercussão mais modesta (VERGUEIRO et al., 2013).

Como a parceria entre os três foi frutífera, pensou-se em torná-la permanente, o que os levou a formular um núcleo de pesquisas sobre os quadrinhos, sugerido à direção da ECA em 1990. 0 nome inicialmente proposto seria Núcleo Interdepartamental de Pesquisas em Histórias em Quadrinhos. No entanto, o título aprovado pela ECA foi simplesmente Núcleo de Pesquisas de Histórias em Quadrinhos. Tal denominação se manteve até 2008, quando o núcleo passou a se chamar Observatório de Histórias em Quadrinhos, nome que perdura até hoje.

Trata-se de um espaço formal para o estudo de quadrinhos na USP, um dos primeiros centros de pesquisa em quadrinhos no mundo vinculado a uma universidade, o que possibilitou pesquisas acadêmicas sobre o tema, tornando o Observatório uma referência internacional (VERGUEIRO et al., 2013). A iniciativa existe há quase 30 anos, tendo realizado atividades, projetos de pesquisa, eventos e cursos, além de contar com um acervo de cerca de 20 mil revistas para consulta de pesquisadores e alunos. (VERGUEIRO, 2017a).

Vergueiro também colaborou com a organização da Gibiteca Henfil, em São Paulo, além de criar uma disciplina chamada Histórias em Quadrinhos, Informação e Educação, a primeira sobre quadrinhos no programa de pós-graduação em Ciências da Comunicação da ECA-USP. A experiência nesta disciplina gerou o livro Como usar histórias em quadrinhos na sala de aula ${ }^{10}$, publicado em 2004 (VERGUEIRO et al., 2013). 0 pesquisador passou então a orientar pesquisas exclusivamente relacionadas a quadrinhos na pós-graduação em Ciências

\footnotetext{
${ }^{10}$ RAMA, Angela; VERGUEIRO, Waldomiro (Org.). Como usar as histórias em quadrinhos na sala de aula. São Paulo: Contexto, 2004. Apud Vergueiro et al. (2013).
} 
da Comunicação da ECA-USP. Paralelamente, Vergueiro ainda contribuiu com artigos para veículos externos, como o site Omelete, a revista $H Q$ Express e o jornal Graphiq.

Em 1999, o pesquisador americano John Lent criou a revista International Journal of Comic Art. Conforme o próprio Vergueiro (2017b), ele foi convidado para fazer parte do conselho consultivo internacional da revista. Já no primeiro número, havia um artigo seu acerca dos quadrinhos brasileiros. Ao longo dos anos, o autor publicou diversos artigos nesta revista, escrevendo sempre sobre a produção nacional.

Vergueiro assumiu a disciplina de graduação Editoração de Histórias em Quadrinhos em 1999, com a aposentadoria de Luiz Cagnin (VERGUEIRO et al., 2013). Ainda naquele ano, Vergueiro buscou maior regularidade nas atividades do Núcleo de Pesquisa em Histórias em Quadrinhos, propondo a realização de um encontro mensal, denominado Colóquios Científicos. Realizados todas as primeiras sextas-feiras de cada mês e abertos a pesquisadores, alunos e interessados em geral, nos colóquios ocorrem discussões de textos científicos sobre quadrinhos, apresentação de trabalhos recentes, além da participação de convidados. Atualmente, Vergueiro é o coordenador do Observatório de Histórias em Quadrinhos, enquanto Roberto Elísio dos Santos, da Universidade de São Caetano do Sul, é o vice. Paulo Ramos, professor da UNIFESP e Nobu Chinen, docente da Faculdade Oswaldo Cruz, também são prolíficos pesquisadores do tema envolvidos com o Observatório. Juntos, organizam ainda as Jornadas Internacionais de Quadrinhos, evento da USP do qual nos ocuparemos mais adiante. (VERGUEIRO et al., 2013).

O Brasil foi um dos primeiros países a ter uma especialização dedicada aos quadrinhos, a partir do curso de Especialização em Histórias em Quadrinhos, que funcionou na USP de 1991 a 1993. Tudo começou quando, ao final de 1989, Álvaro de Moya, Antonio Luiz Cagnin e Waldomiro Vergueiro encaminharam a proposta da especialização ao então diretor da ECA, José Marques de Melo. A ideia surgiu a partir das experiências na Comissão de Eventos sobre Histórias em Quadrinhos, gerando um programa composto por 360 horas de variadas matérias. 0 curso teve boa repercussão e muitos inscritos. Dependia, porém, da verba de inscrições para se perpetuar. Como os três docentes da ECA-USP estavam sozinhos na empreitada de organização da especialização, todas as questões burocráticas, tais como pagamentos, contratações, acompanhamento e planejamento recaíam sobre eles - além das aulas ministradas. De modo que, dois anos depois, o curso teve fim. Encerrou suas atividades por questões de gestão administrativa e falta de pessoal, contrariando o plano 
inicial de criar um Mestrado em Histórias em Quadrinhos a partir da experiência da Especialização (VERGUEIRO et al., 2013; VERGUEIRO, 2017b).

O Curso de Especialização em Quadrinhos da ECA, ativo até 1993, chegou a lançar uma revista de divulgação chamada Agaquê. A revista deu lugar, depois, ao Boletim do Núcleo de Histórias em Quadrinhos, que durou cerca de três anos. 0 boletim conquistou um troféu HQMIX (2021), importante prêmio do gênero. A iniciativa das revistas surgiu com a intenção de fomentar o debate em quadrinhos além dos limites da universidade. Uma nova revista Agaquê retornou em 1998 no formato de site, que ficou no ar por cerca de quatro anos. Buscava divulgar artigos reflexivos sobre quadrinhos, frutos de trabalhos de mestrado e doutorado. Devido às dificuldades de logística e infraestrutura, como falta de pessoal e de bolsistas, a revista acabou saindo do ar. Mais tarde, nos anos 2000, com a revitalização do núcleo de pesquisas, foi ao ar outra revista eletrônica, a Nona arte (VERGUEIRO, 2017b).

Atualmente, há duas outras especializações do gênero ativas no país: a Especialização em Histórias em Quadrinhos, promovida pelas Faculdades EST (2021), de São Leopoldo, no Rio Grande do Sul, e a Especialização em Arte Sequencial (UNIVERSIDADE CÂNDIDO MENDES, 2021) , promovida pela Universidade Cândido Mendes, do Rio de Janeiro.

A partir de 2011, foram organizadas as primeiras Jornadas Internacionais de Histórias em Quadrinhos (COMISSÃO ORGANIZADORA..., 2021) e as Jornadas Temáticas de Histórias em Quadrinhos (VERGUEIRO, 2017b), eventos realizados na USP para incentivar novos pesquisadores.

Pode-se afirmar que o advento da internet ajudou a disseminar a pesquisa em quadrinhos no país, ampliando as áreas de interesse e fazendo com que profissionais de áreas distintas da Comunicação se debruçassem sobre o gênero, tornando-o multidisciplinar (VERGUEIRO et al., 2013). Desse modo, para além dos programas de Comunicação, outras pós-graduações brasileiras começaram a receber pesquisadores em quadrinhos. A experiência foi abrindo portas e cada vez mais professores passaram a orientar trabalhos afins (VERGUEIRO, 2017a). Pesquisas relacionadas aos quadrinhos são desenvolvidas atualmente em campos como História, Artes, Comunicação, Matemática, Linguística, Direito, Letras, Desenho Industrial, Filosofia, Ciência da Informação e Teologia, como pode ser verificado no quadro 1 da seção "Iniciativas" deste artigo. 
Com o aumento da produção acadêmica sobre quadrinhos no Brasil, movimenta-se um ciclo de produção que influi até mesmo junto aos desenhistas. Também há cada vez mais sites sobre a temática. Sonia Luyten, a propósito, fez uma coluna no site Universohq com um banco de teses acadêmicas, para facilitar o seu acesso (VERGUEIRO et al., 2013).

Entre outros pesquisadores que dedicaram esforços ao estudo de quadrinhos, se destacam , por exemplo, nomes como João Elias Nery, autor da obra Graúna e Rebordosa: o humor gráfico brasileiro de 1970 e 1980 (NERY, 2006), bem como Elydio dos Santos Neto (falecido), Diamantino da Silva, Reinaldo de Oliveira (falecido), Ionaldo Cavalcanti (falecido), Hiron Goidanich e Rogério de Campos. Todos contribuíram para transformar os quadrinhos em objeto de estudo acadêmico (VERGUEIRO, 2017b ).11

\subsection{Vitrines da pesquisa em quadrinhos}

Entre os centros dedicados à pesquisa e à preservação dos quadrinhos no país está a Gibiteca de Curitiba (PREFEITURA MUNICIPAL..., 2012), criada em 1982 e prestes a completar 40 anos de atividade em 15 de outubro de 2022. Localizada no edifício do Solar do Barão, no centro da capital paranaense, trata-se da primeira gibiteca do Brasil e uma das primeiras do mundo. Nela ocorrem exposições, concursos, palestras, feiras, cursos e oficinas. Além de ser um centro de formação de desenhistas, o local reúne uma biblioteca especializada com mais de 33 mil títulos, divididos em gêneros como comics, infantil e mangá.

Nesse quesito destaca-se ainda a Gibiteca Henfil, que leva o nome do célebre cartunista mineiro. Criada em 1990 pelo pesquisador Henrique Magalhães em João Pessoa, foi a segunda gibiteca do país. Situada no Espaço cultural José Lins do Rego, na capital paraibana, a gibiteca conta atualmente com um acervo de cerca de quatro mil exemplares, contendo, entre outros, raridades, fanzines e obras estrangeiras. 0 espaço abriga ainda exposições, mesas redondas, debates, sessões de autógrafos, palestras e oficinas.

Em matéria de premiações relacionadas aos quadrinhos, há, desde 1988, o troféu HQMIX (2021), do qual Sonia Luyten foi presidente por três anos. Neste troféu, Luyten incluiu a categoria de melhores teses (TCC, mestrado e doutorado), como incentivo à

\footnotetext{
11 Pesquisadores como Vergueiro (2017b), contudo, ainda se mostram reticentes quanto à viabilidade de iniciativas como um mestrado direcionado aos quadrinhos no Brasil. Exemplo disso é caso de Henrique Magalhães, da UFPB, que teve o projeto de um mestrado específico em quadrinhos rejeitado pela CAPES.
} 
pesquisa e também visando diminuir a distância entre pesquisador e desenhista (VERGUEIRO et al., 2013). 0 troféu premia ainda a categoria de melhor livro teórico. Hoje, fazem parte de sua comissão organizadora pesquisadores como Waldomiro Vergueiro, Nobu Chinen e Sonia Luyten.

Desde 2017, o Prêmio Jabuti (2019), maior premiação literária brasileira, incluiu a categoria Histórias em Quadrinhos dentro do eixo de Literatura, premiando, assim, a obra eleita como a melhor de cada ano. Tal inclusão não se deu gratuitamente: foi necessário um abaixo-assinado firmado por grandes nomes do quadrinho nacional, como Laerte Coutinho, Marcelo Quintanilha, Fábio Moon e Gabriel Bá.

Há ainda o Prêmio Angelo Agostini, existente desde 1984, que, entre outras categorias, premia a cada edição um Mestre do Quadrinho Nacional, reconhecimento já conferido a pesquisadores, como é o caso de Sonia Luyten.

Finalmente, desde 1974, é organizado no interior de São Paulo o Salão Internacional de Humor de Piracicaba (2021), contando com exposições e mostras que contemplaram grandes nomes do humor gráfico nacional, como Millôr Fernandes, Ziraldo, Jaguar, Fortuna, Henfil, Luis Fernando Verissimo, Paulo e Chico Caruso, Angeli, Laerte, Glauco, entre outros. 0 evento conta ainda com premiações que abrangem cerca de 12 categorias artísticas relacionadas ao humor gráfico.

Vale citar também o trabalho de três editoras voltadas para a publicação de livros acadêmicos sobre quadrinhos. São elas a Editora Criativo, a Editora Peirópolis e a Editora Marca de Fantasia - esta última fundada pelo pesquisador Henrique Magalhães.

Em se tratando de sites especializados, há o Guia dos Quadrinhos (DIOGO, 2021), página colaborativa de caráter enciclopédico, onde encontram-se biografias de quadrinistas e de figuras ligadas ao tema.

\section{Mapeamento das iniciativas de pesquisa em quadrinhos}

Como é próprio de todo recorte investigativo, os esforços dos pesquisadores supracitados, tais como Vergueiro, Chinen, Ramos e Santos dando conta de uma memória da pesquisa em quadrinhos no Brasil, com especial ênfase à experiência da ECA-USP, não são exaustivos, ao eleger um limite específico e deixar de abordar iniciativas e pesquisadores de outras regiões do país. Seria praticamente impossível contemplar num só trabalho a 
descrição da totalidade de pesquisas de um determinado campo do conhecimento, o que faz de toda tentativa do gênero uma opção conscientemente limitada. Escolhe-se deliberadamente abordar uma ou outra vertente. A seção anterior não procurou, nem poderia, portanto, esgotar o tema. Interessante reflexão acerca do assunto oferece Célio Guimarães, em coluna publicada no site paranaense Zé Beto (GUIMARÃES, 2013), dando conta de certas omissões do livro de Vergueiro (et al., 2013). Seguindo o mesmo princípio, indicamos, a seguir, algumas das empreitadas relacionadas à pesquisa em quadrinhos no país.

\subsection{Iniciativas}

A seguir, buscou-se levantar e sistematizar uma série de iniciativas relacionadas à pesquisa em quadrinhos no Brasil, muitas das quais ainda em atividade, seja na forma de grupos de pesquisa, espaços, associações, revistas acadêmicas, cursos acadêmicos, eventos, sites especializados, prêmios e editoras que investem na pesquisa em quadrinhos. A listagem, não exaustiva, orientou-se pela publicidade e rastreabilidade da iniciativa. Especificamente para o levantamento dos grupos de pesquisa, também utilizou-se a plataforma Lattes Diretório dos Grupos de Pesquisa no Brasil, do CNPq (BRASIL, 2021), onde, para os termos "quadrinhos" e "arte sequencial" foram encontradas 44 ocorrências de grupos, dos quais, após análise mais detida, 28 detêm-se especificamente ao estudo dos quadrinhos, em oposição a abordagens mais tangenciais das demais ocorrências. Desses 28 grupos certificados pelo CNPq (BRASIL, 2021), que detém suas atenções especificamente aos quadrinhos, há ocorrências pertencentes a diversas áreas do conhecimento, tais como História, Artes, Comunicação, Matemática, Linguística, Direito, Letras, Desenho Industrial, Filosofia, Ciência da Informação e Teologia, constatando que os quadrinhos são objeto de estudo em variados campos.

No decorrer da pesquisa, foram localizados ainda outros registros de grupos e espaços de pesquisa não indexados no CNPq (BRASIL, 2021), porém igualmente atuantes. A partir dos dados encontrados, verifica-se que estes grupos de pesquisa estão concentrados majoritária, mas não exclusivamente, em instituições de ensino públicas. Há ainda ocorrências em instituições de ensino privadas, além de iniciativas independentes, não necessariamente vinculadas a instituições de ensino. Os grupos e espaços de pesquisa 
localizados estão distribuídos por 17 estados brasileiros, indicando uma ampla abrangência do estudo de quadrinhos no país. Foram encontrados também cinco registros de revistas, sete registros de cursos acadêmicos de variados níveis, 16 ocorrências de eventos acadêmicos, cinco registros de prêmios especializados, três editoras dedicadas à publicação de textos acadêmicos sobre quadrinhos e um site enciclopédico relacionado ao tema.

Quadro 1 - Grupos de pesquisa presentes no Diretório do CNPq.

\begin{tabular}{|c|c|c|c|}
\hline Grupo & Sede & Criação & Área \\
\hline $\begin{array}{l}\text { A História nos quadrinhos: } \\
\text { uma análise da apropriação de } \\
\text { temas históricos nas HQ's }\end{array}$ & IFPB & 2020 & História \\
\hline $\begin{array}{l}\text { Arte, religião e memória } \\
\text { (ARTEMI) }\end{array}$ & UEPA & 2015 & Artes \\
\hline Ciberarte-educação & UFG & 2000 & Artes \\
\hline $\begin{array}{c}\text { Comunicação e educação } \\
\text { midiática }\end{array}$ & FURB & 2016 & Comunicação \\
\hline $\begin{array}{l}\text { Excelsior! Grupo de Pesquisa } \\
\text { em Religião e Cultura da Mídia }\end{array}$ & UNASP & 2016 & Comunicação \\
\hline $\begin{array}{c}\text { Expressão Gráfica e } \\
\text { Representação da Forma }\end{array}$ & UFSC & 1997 & Matemática \\
\hline $\begin{array}{c}\text { Grupo de Pesquisa em Análise } \\
\text { da Fotografia e das Narrativas } \\
\text { Visuais e Gráficas } \\
\text { (GRAFO/NAVI) }\end{array}$ & UFF & 2010 & Comunicação \\
\hline $\begin{array}{c}\text { Grupo de Estudo de História } \\
\text { em Quadrinhos (GIBI) }\end{array}$ & UnB & 2014 & Comunicação \\
\hline $\begin{array}{c}\text { Grupo de Pesquisa "Oficina } \\
\text { Invisível de Investigação em } \\
\text { Quadrinhos" }\end{array}$ & UFC & 2019 & Comunicação \\
\hline $\begin{array}{c}\text { Grupo de Pesquisa em } \\
\text { Semiótica da UNESP (GPS- } \\
\text { UNESP) }\end{array}$ & UNESP & 2003 & Linguística \\
\hline $\begin{array}{c}\text { Grupo de Pesquisa } \\
\text { Interdisciplinar em Arte } \\
\text { Sequencial, Mídias e Cultura } \\
\text { Pop }\end{array}$ & $\begin{array}{l}\text { Faculdades } \\
\text { EST }\end{array}$ & 2013 & Teologia \\
\hline $\begin{array}{c}\text { Grupo de Pesquisa Justiça em } \\
\text { Quadrinhos }\end{array}$ & UNIFOR & 2014 & Direito \\
\hline $\begin{array}{l}\text { Grupo de Pesquisa sobre } \\
\text { Quadrinhos (GRUPESQ) }\end{array}$ & UNIFESP & 2013 & Letras \\
\hline História, impressos e imagens & UFPel & 2013 & História \\
\hline
\end{tabular}




\begin{tabular}{|c|c|c|c|}
\hline $\begin{array}{c}\text { Laboratório de Artes para } \\
\text { Ciências e Mídias Educativas }\end{array}$ & UVA RJ & 2019 & $\begin{array}{c}\text { Desenho } \\
\text { Industrial }\end{array}$ \\
\hline $\begin{array}{c}\text { Linguagens, discurso e } \\
\text { sociedade (LINDES) }\end{array}$ & IFBA & 2019 & Linguística \\
\hline Linguagens audiovisuais & UNIVILLE & 2003 & Letras \\
\hline $\begin{array}{c}\text { Migrantes na literatura e nas } \\
\text { histórias em quadrinhos }\end{array}$ & UNILAB & 2018 & Letras \\
\hline Núcleo de Filosofias da Criação & UFRJ & 2015 & Filosofia \\
\hline $\begin{array}{c}\text { Núcleo de Material Pedagógico } \\
\text { e Ensino de História } \\
\text { (NUMPEH) }\end{array}$ & $\begin{array}{c}\text { Colégio } \\
\text { Pedro II }\end{array}$ & 2018 & História \\
\hline $\begin{array}{c}\text { Núcleo de Pesquisa em } \\
\text { Narrativas Gráficas }\end{array}$ & UFMG & 2011 & Artes \\
\hline $\begin{array}{c}\text { Núcleo de Pesquisa em } \\
\text { Quadrinhos (NuPeQ) }\end{array}$ & UEMS & 2012 & Letras \\
\hline $\begin{array}{c}\text { Oficinas de escrita, histórias em } \\
\text { quadrinhos e tradução: teoria da } \\
\text { literatura e práticas literárias }\end{array}$ & UFSM & 2018 & Letras \\
\hline $\begin{array}{c}\text { Grupo de Pesquisa em Leitura, } \\
\text { Escrita e Narrativa (PLENA) }\end{array}$ & UFS & 2015 & Ciência da \\
\hline $\begin{array}{c}\text { Poéticas Artísticas e Processos } \\
\text { de Criação }\end{array}$ & UFG & 2018 & Artes \\
\hline $\begin{array}{c}\text { Quadrinhos e análise } \\
\text { linguística }\end{array}$ & UEL & 2016 & Linguística \\
\hline $\begin{array}{c}\text { Quadro a quadro } \\
\text { Universos Paralelos: Arte } \\
\text { Sequencial, Mediação Cultural } \\
\text { práticas pedagógicas }\end{array}$ & UNILASALLE & 2019 & Teologia \\
\hline
\end{tabular}

Fonte: Lattes CNPq (BRASIL, 2021).

Quadro 2 - Grupos e espaços de pesquisa ausentes do Diretório do CNPq.

\begin{tabular}{|c|c|c|}
\hline Grupo & Sede & Criação \\
\hline $\begin{array}{c}\text { Associação dos Pesquisadores em Arte } \\
\text { Sequencial (ASPAS) }\end{array}$ & $\begin{array}{c}\text { Casa de Leitura Lya } \\
\text { Botelho - Leopoldina } \\
\text { MG }\end{array}$ & 2012 \\
\hline $\begin{array}{c}\text { Centro de Desenvolvimento e } \\
\text { Incentivo Cultural às Histórias em } \\
\text { Quadrinhos (CDICHQ) }\end{array}$ & Recife PE & - \\
\hline $\begin{array}{c}\text { Espaço de Pesquisa e Oficina Pagu } \\
\text { (Espaço Pop) }\end{array}$ & $\begin{array}{c}\text { Biblioteca Central } \\
\text { UnB - Brasília DF }\end{array}$ & 2017 \\
\hline $\begin{array}{c}\text { Grupo de Estudos e Pesquisas } \\
\text { Professora Sonia Luyten }\end{array}$ & $\begin{array}{c}\text { Gibiteca de Santos - } \\
\text { Santos SP }\end{array}$ & 2018 \\
\hline Grupo de Pesquisa Comunicação, & Centro de Estudos & 2012 \\
\hline
\end{tabular}




\begin{tabular}{|c|c|c|}
\hline Imagem e Discurso & $\begin{array}{c}\text { em Design da } \\
\text { Imagem, Escola de } \\
\text { Design UEMG - Belo } \\
\text { Horizonte MG }\end{array}$ & \\
\hline $\begin{array}{c}\text { Grupo de Pesquisa Criação e Ciberarte } \\
\text { (Cria Ciber) }\end{array}$ & $\begin{array}{c}\text { Faculdade de Artes } \\
\text { Visuais UFG - } \\
\text { Goiânia GO }\end{array}$ & - \\
\hline $\begin{array}{c}\text { Grupo de Pesquisa e Histórias em } \\
\text { Quadrinhos, antigo Grupo de Pesquisas } \\
\text { e Estudo de Histórias em Quadrinhos } \\
\text { (GRUPEHQ) }\end{array}$ & Natal RN & 1971 \\
\hline $\begin{array}{c}\text { Grupo de Pesquisa em Histórias em } \\
\text { Quadrinhos Imaginário }\end{array}$ & $\begin{array}{c}\text { UFPB - João Pessoa } \\
\text { PB }\end{array}$ & - \\
\hline $\begin{array}{c}\text { Grupo de Pesquisa em Produções } \\
\text { Literárias e Culturais para Crianças e } \\
\text { Jovens (PLCC) }\end{array}$ & $\begin{array}{c}\text { FFLCH USP - São } \\
\text { Paulo SP }\end{array}$ & - \\
\hline $\begin{array}{c}\text { Laboratório Interdisciplinar de } \\
\text { Pesquisa e Ensino em Entretenimento } \\
\text { e Mídias (LIPEEM) }\end{array}$ & $\begin{array}{c}\text { UFPel - Pelotas RS } \\
\text { (NIQ) }\end{array}$ & - \\
\hline Núcleo de Ilustrac̃a e Quadrinhos & Escola de Design \\
UEMG - Belo & - \\
\hline $\begin{array}{c}\text { Hobservatório de Histórias em } \\
\text { Quadrinhos, antigo Núcleo de }\end{array}$ & $\begin{array}{c}\text { ECA-USP - São Paulo } \\
\text { SP }\end{array}$ & 1990 \\
Pesquisas em Histórias em Quadrinhos & & \\
\hline
\end{tabular}

Fonte: Dados da pesquisa.

Quadro 3 - Revistas.

\begin{tabular}{|c|c|c|c|}
\hline Nome & Vinculação & Status & Qualis 2019 \\
\hline Agaquê & ECA-USP & Inativo & - \\
\hline $\begin{array}{c}\text { Boletim do Núcleo de Histórias } \\
\text { em Quadrinhos }\end{array}$ & ECA-USP & Inativo & - \\
\hline Imaginário & UFPB & Ativo & B4 \\
\hline Nona Arte & ECA-USP & Ativo & B4 \\
\hline Quadreca & ECA-USP & Inativo & - \\
\hline
\end{tabular}

Fonte: Dados da pesquisa.

Quadro 4 - Cursos acadêmicos.

\begin{tabular}{|c|c|c|c|}
\hline Nome & Local & Nível & Status \\
\hline $\begin{array}{c}\text { Curso de Especialização } \\
\text { em Arte Sequencial }\end{array}$ & $\begin{array}{c}\text { Universidade } \\
\text { Cândido Mendes - } \\
\text { Rio de Janeiro RJ }\end{array}$ & Especialização & Ativo \\
\hline
\end{tabular}




\begin{tabular}{|c|c|c|c|}
\hline $\begin{array}{c}\text { Curso de Especialização } \\
\text { em Histórias em } \\
\text { Quadrinhos }\end{array}$ & $\begin{array}{c}\text { ECA-USP - São } \\
\text { Paulo SP }\end{array}$ & Especialização & $\begin{array}{c}\text { Inativo } \\
\text { (1991 a } \\
1993)\end{array}$ \\
\hline $\begin{array}{c}\text { Curso de Especialização } \\
\text { em Histórias em } \\
\text { Quadrinhos }\end{array}$ & $\begin{array}{c}\text { Faculdades EST - } \\
\text { São Leopoldo RS }\end{array}$ & Especialização & Ativo \\
\hline $\begin{array}{c}\text { Editoração em História } \\
\text { em Quadrinhos }\end{array}$ & $\begin{array}{c}\text { ECA-USP - São } \\
\text { Paulo SP }\end{array}$ & $\begin{array}{c}\text { Disciplina de } \\
\text { Graduação }\end{array}$ & $\begin{array}{c}\text { Ativo } \\
\text { (desde } \\
1972)\end{array}$ \\
\hline $\begin{array}{c}\text { Histórias em Quadrinhos } \\
\text { Histórias em Quadrinhos, } \\
\text { Cinema e Televisão }\end{array}$ & $\begin{array}{c}\text { Pós-Graduação em } \\
\text { Ciências da } \\
\text { Comunicação } \\
\text { ECA-USP - São } \\
\text { Paulo SP }\end{array}$ & $\begin{array}{c}\text { Disciplina de } \\
\text { Pós- } \\
\text { Graduação }\end{array}$ & Ativo \\
\hline $\begin{array}{c}\text { História em Quadrinhos: } \\
\text { Leitura e Interpretação }\end{array}$ & $\begin{array}{c}\text { Pós-Graduação em } \\
\text { Ciências da } \\
\text { Comunicação } \\
\text { ECA-USP - São } \\
\text { Paulo SP }\end{array}$ & $\begin{array}{c}\text { Disciplina de } \\
\text { Pós- } \\
\text { Graduação }\end{array}$ & Ativo \\
\hline
\end{tabular}

Fonte: Dados da pesquisa.

Quadro 5 - Eventos.

\begin{tabular}{|c|c|c|c|}
\hline Nome & Local & Criação & Status \\
\hline ASPAS Norte & $\begin{array}{c}\text { Universidades } \\
\text { da região } \\
\text { Norte }\end{array}$ & 2018 & Ativo \\
\hline $\begin{array}{c}\text { Colóquio Regional Sul em Arte } \\
\text { Sequencial }\end{array}$ & $\begin{array}{c}\text { Faculdades } \\
\text { EST - São } \\
\text { Leopoldo RS } \\
\text { UNIFOR - } \\
\text { Fortaleza CE }\end{array}$ & 2015 & Ativo \\
\hline $\begin{array}{c}\text { Colóquio Justiça em Quadrinhos } \\
\text { e Filosofia do Direito }\end{array}$ & $\begin{array}{c}\text { EBA UFRJ - } \\
\text { Rio de Janeiro } \\
\text { RJ }\end{array}$ & 2019 & Ativo \\
\hline $\begin{array}{c}\text { EBANIMADA } \\
\text { Encontro de Quadrinhos de } \\
\text { Brasília }\end{array}$ & $\begin{array}{c}\text { UnB / Caixa } \\
\text { Cultural - } \\
\text { Brasília DF }\end{array}$ & 2015 & Ativo \\
\hline $\begin{array}{c}\text { Encontro Nacional de Estudos } \\
\text { sobre Quadrinhos e Cultura Pop }\end{array}$ & $\begin{array}{c}\text { UFPE - Recife } \\
\text { PE }\end{array}$ & 2011 a & Inativo \\
\hline $\begin{array}{c}\text { Encontro Nacional dos Grupos } \\
\text { de Pesquisa sobre Cultura Pop }\end{array}$ & $\begin{array}{c}\text { Faculdades } \\
\text { EST - São } \\
\text { Leopoldo RS }\end{array}$ & 2015 & Ativo \\
\hline
\end{tabular}




\begin{tabular}{|c|c|c|c|}
\hline Entre ASPAS & $\begin{array}{c}\text { CEFET - } \\
\text { Leopoldina MG }\end{array}$ & 2013 & Ativo \\
\hline $\begin{array}{c}\text { Fórum Nacional de } \\
\text { Pequisadores em Arte } \\
\text { Sequencial (FNPAS) }\end{array}$ & $\begin{array}{c}\text { Universidades } \\
\text { brasileiras } \\
\text { itinerante) }\end{array}$ & 2012 & Ativo \\
\hline $\begin{array}{c}\text { Jornada de Histórias em } \\
\text { Quadrinhos }\end{array}$ & $\begin{array}{c}\text { UnB - Brasília } \\
\text { DF }\end{array}$ & 2018 & Ativo \\
\hline $\begin{array}{c}\text { Jornadas Internacionais de } \\
\text { Histórias em Quadrinhos }\end{array}$ & $\begin{array}{c}\text { ECA-USP - São } \\
\text { Paulo SP }\end{array}$ & 2011 & Ativo \\
\hline $\begin{array}{c}\text { Panorama Contemporâneo das } \\
\text { Histórias em Quadrinhos no } \\
\text { Brasil }\end{array}$ & $\begin{array}{c}\text { NELI UFPE - } \\
\text { Recife PE }\end{array}$ & 2017 & Inativo \\
\hline $\begin{array}{c}\text { Internacional de Histórias em } \\
\text { Quadrinhos }\end{array}$ & $\begin{array}{c}\text { MASP - São } \\
\text { Paulo SP }\end{array}$ & Novembro \\
de 1970 & Inativo \\
\hline $\begin{array}{c}\text { Primeira Exposição } \\
\text { Internacional de Histórias em } \\
\text { Quadrinhos }\end{array}$ & $\begin{array}{c}\text { Centro Cultura } \\
\text { e Progresso - } \\
\text { São Paulo SP }\end{array}$ & Junho de & Inativo \\
\hline $\begin{array}{c}\text { Semana Internacional de } \\
\text { Quadrinhos (SIQ) }\end{array}$ & $\begin{array}{c}\text { ECO UFRJ - Rio } \\
\text { de Janeiro RJ }\end{array}$ & 2016 & Ativo \\
\hline $\begin{array}{c}\text { Seminário de Pesquisa sobre } \\
\text { Quadrinhos (SEPESQ) }\end{array}$ & $\begin{array}{c}\text { UNIFESP - } \\
\text { Guarulhos SP }\end{array}$ & 2015 & Ativo \\
\hline
\end{tabular}

Fonte: Dados da pesquisa.

Quadro 6 - Prêmios.

\begin{tabular}{|c|c|}
\hline Nome & Criação \\
\hline $\begin{array}{l}\text { Prêmio Ângelo Agostini - Categoria Mestre do Quadrinho } \\
\text { Nacional }\end{array}$ & 1984 \\
\hline $\begin{array}{c}\text { Prêmio Jabuti - Eixo Literatura - Categoria Histórias em } \\
\text { Quadrinhos }\end{array}$ & 2017 \\
\hline Salão Internacional de Humor de Piracicaba & 1974 \\
\hline $\begin{array}{c}\text { Troféu HQMIX - Categorias Livro Teórico, TCC, Mestrado e } \\
\text { Doutorado }\end{array}$ & 1989 \\
\hline
\end{tabular}

Fonte: Dados da pesquisa.

Quadro 7 - Editoras especializadas.

\begin{tabular}{|c|c|}
\hline Nome & Site \\
\hline Criativo & http://editoracriativo.com.br/ \\
\hline Marca de Fantasia & https://www.marcadefantasia.com/ \\
\hline Peirópolis & https://www.editorapeiropolis.com.br/ \\
\hline
\end{tabular}

Fonte: Dados da pesquisa. 
Quadro 8 - Site especializado.

\begin{tabular}{|c|c|}
\hline Nome & Endereço \\
\hline Guia dos Quadrinhos & http://www.guiadosquadrinhos.com/ \\
\hline
\end{tabular}

Fonte: Dados da pesquisa.

\section{Considerações finais}

A partir do levantamento e das considerações aqui apresentados, conclui-se que a pesquisa em quadrinhos no país, desde seus primórdios na década de 1950, acompanhou o desenvolvimento da pesquisa em comunicação social, área à qual esteve ligada de maneira mais organizada, enfrentando relativa resistência em sua trajetória, tanto por parte da sociedade em geral quanto da academia. Pouco a pouco, graças ao trabalho de pesquisadores de diversas regiões do Brasil, incluindo aqueles mais detidamente referidos neste artigo, relacionados às iniciativas da ECA-USP, como Álvaro de Moya, Francisco Araújo, Sonia Maria Bibe Luyten, Luiz Antonio Cagnin, Waldomiro Vergueiro e, mais recentemente, autores como Paulo Ramos, Nobu Chinen e Roberto Elisio dos Santos, a área teve nítida expansão.

Constatou-se, também, que, no Brasil, as histórias em quadrinhos seguem os caminhos trilhados em outros países, tanto como produto veiculado nas mídias, quanto na pesquisa acerca de sua inserção na sociedade. As controvérsias observadas nos EUA e em países da Europa refletiram entre nós e influenciaram a compreensão do papel desta linguagem para os diversos públicos que a acessam. Por haver produção voltada ao público infantil, teses como as existentes no livro Seduction of the Innocent ${ }^{12}$ repercutiram por aqui, assim como o conceito de Indústria Cultural, acentuando aspectos negativos das histórias em quadrinhos sobre este público.

Em outro registro, o livro Para leer al Pato Donald ${ }^{13}$ apresentou crítica que pode ser incluída no contexto da denúncia ao Imperialismo Cultural que faria parte da estratégia de dominação dos EUA. Apesar de a crítica dirigir-se aos quadrinhos dos EUA, também incidiu sobre a produção e circulação desta linguagem e no universo da pesquisa realizada no Brasil. A produção de histórias em quadrinhos críticas, como é possível observar no trabalho, por exemplo, de Henfil, foi analisada por Moacy Cirne, pesquisador ligado a

\footnotetext{
12 WERTHAM, Fredric. Seduction of the innocent. New York: Rinehart \& Company, 1954. Apud Vergueiro et al. (2013).

13 DORFMAN, Ariel; MATTELART, Armand. Para leer al pato Donald. Valparaíso: Ediciones Universitarias de Valparaíso, 1971. Apud Vergueiro; Santos (2014).
} 
instituições no Rio de Janeiro, como obra de "descolonização". Criação e crítica colocam os quadrinhos como parte da resistência à cultura norte-americana.

A pesquisa e o ensino em quadrinhos mantiveram vínculo privilegiado com a área de Comunicação Social. No entanto, como é possível observar no levantamento apresentado, implantou-se também em outras áreas, expandindo o olhar acadêmico, principalmente em cursos de pós-graduação e núcleos de pesquisa interdisciplinares ou ligados a áreas como Artes, História, Pedagogia, Letras, entre outras, o que remete à capacidade dos quadrinhos de dialogar com diversos públicos e áreas acadêmicas e de inserir-se como parte da cultura da mídia.

Apesar de este estudo ter como principal foco a pesquisa desenvolvida no âmbito da ECA-USP, o levantamento possibilitou identificar a existência de grupos de pesquisa, cursos, acadêmicos ou não, e publicações em instituições em diversas regiões do país, configurando a relevância dos estudos em quadrinhos como parte das práticas institucionalizadas ao longo das últimas décadas.

Verifica-se, contudo, a necessidade de ampliação contínua das oportunidades de estudo, por intermédio, por exemplo, da instituição de programas de mestrado e doutorado voltados especificamente aos quadrinhos, proposta já realizada por Henrique Magalhães, no âmbito da UFPB, porém sem aprovação da CAPES.

\section{Referências}

ASSOCIAÇÃO DE PESQUISADORES EM ARTE SEQUENCIAL. Blog da ASPAS. Minas Gerais, 2021. Página inicial. Disponível em: http://blogdaaspas.blogspot.com/. Acesso em: 30 jun. 2021.

BRASIL. Conselho Nacional de Desenvolvimento Científico e Tecnológico. Diretório dos Grupos de Pesquisa no Brasil. Brasília: CNPq, 2021. Disponível em: http://lattes.cnpq.br/web/dgp. Acesso em: 30 jun. 2021.

COMISSÃO ORGANIZADORA DAS JORNADAS INTERNACIONAIS DE HISTÓRIAS EM QUADRINHOS. Jornadas Internacionais de Histórias em Quadrinhos. São Paulo, 2021. Página inicial. Disponível em: https://www.jornadasinternacionais.com.br/. Acesso em: 30 jun. 2021.

DIOGO, Edison. Guia dos Quadrinhos. [S.I.], 2021. Página inicial. Disponível em: http://www.guiadosquadrinhos.com/. Acesso em: 30 jun. 2021. 
FACULDADES EST. Especialização em Histórias em Quadrinhos. [S.I.], 2021. Disponível em: http://est.edu.br/pos-graduacao/especializacao/curso/especializacao-em-historiasem-quadrinhos. Acesso em: 30 jun. 2021.

FOGEL, Israel. A magia da Nona Arte. 1. ed. São Paulo: Clube de Autores, 2019.

FRANÇA, Francisco. Quinze anos depois, a Gibiteca Henfil reabre as portas. Jornal da Paraíba, Paraíba, 14 ago. 2015. Disponível em:

https://www.jornaldaparaiba.com.br/cultura/quinze-anos-depois-a-gibiteca-henfil-reabreas-portas.html. Acesso em: 30 jun. 2021.

GIL, Antonio Carlos. Como elaborar projetos de pesquisa. 4. ed. São Paulo: Editora Atlas, 2002.

GRUPO DE PESQUISAS SOBRE QUADRINHOS. Seminário de Pesquisa sobre Quadrinhos. [S.I.], 2019. Disponível em: https://sepesq.wordpress.com/. Acesso em: 30 jun. 2021.

GUIMARÃES, Célio Heitor. Estudiosos dos quadrinhos. Está faltando gente aí! Zé Beto, Curitiba, 2013. Disponível em: http://www.zebeto.com.br/2013/08/21/estudiosos-dosquadrinhos-esta-faltando-gente-ai/. Acesso em: 30 jun. 2021.

NERY, João Elias. Graúna e Rebordosa: o humor gráfico brasileiro de 1970 e 1980. São Paulo: Terras do Sonhar / Edições Pulsar, 2006.

PREFEITURA MUNICIPAL DE CURITIBA. Primeira do Brasil, Gibiteca de Curitiba completa 30 anos. Curitiba, 2012. Disponível em:

https://www.curitiba.pr.gov.br/noticias/primeira-do-brasil-gibiteca-de-curitiba-completa30-anos/27780. Acesso em: 30 jun. 2021.

PRÊMIO JABUTI. Premiados 2019. [S.I.], 2019. Disponível em: https://www.premiojabuti.com.br/premiados-por-edicao/premiacao/?ano=2019. Acesso em: 30 jun. 2021.

SALÃO INTERNACIONAL DE HUMOR DE PIRACICABA. História. Piracicaba, 2021. Disponível em: https://salaointernacionaldehumor.com.br/historia/. Acesso em: 30 jun. 2021.

TROFÉU HQMIX. História do HQMIX. São Paulo, 2021. Disponível em: https://hqmix.com.br/sobre. Acesso em: 30 jun. 2021.

UNIVERSIDADE CÂNDIDO MENDES. Especialização em Arte Sequencial. Rio de Janeiro, 2021. Disponível em: https://www.universia.com.br/estudos/universidade-candidomendes/especializacao-arte-sequencial/st/236380. Acesso em: 30 jun. 2021.

VERGUEIRO, Waldomiro de Castro Santos. Observatório de Histórias em Quadrinhos, São Paulo, 2021. Página inicial. Disponível em:

http://observatoriodehistoriasemquadrinhos.blogspot.com/. Acesso em: 30 jun. 2021. 
VERGUEIRO, Waldomiro de Castro Santos. Pesquisa Acadêmica em Histórias em Quadrinhos. 1. ed. São Paulo: Criativo, 2017. (a)

VERGUEIRO, Waldomiro de Castro Santos. Panorama das Histórias em Quadrinhos no Brasil. 1. ed. São Paulo: Peirópolis, 2017. (b)

VERGUEIRO, Waldomiro de Castro Santos; RAMOS, Paulo; CHINEN, Nobu (orgs.). Os Pioneiros no Estudo de Quadrinhos no Brasil. 1. ed. São Paulo: Criativo, 2013.

VERGUEIRO, Waldomiro de Castro Santos; SANTOS, Roberto Elísio dos. As histórias em quadrinhos como objeto de estudo das teorias da comunicação. Comunicação IberoAmericana: os Desafios da Internacionalização. Universidade do Minho, 2014, p. 4365-4380.

\title{
Analysis of research on comic books in Brazil: a contribution from ECA-USP
}

\begin{abstract}
This article aims to survey the history of research on comic books in Brazil, especially within the scope of Escola de Comunicação e Artes (School of Communication and Arts) of the University of São Paulo, pinpointing authors and relevant initiatives. This study combines bibliographic research and literature review of works on comic books. It retraces a possible path, within the limits set by the study, showing the trajectory of Brazilian research on comics from its beginning to this date. As studies grow in number and visibility, an initial resistance to the research on comics, on the part of cultural elites and academic peers, is as noticeable as the gradual acceptance of this field of investigation. The perspectives and limits considered by area researchers are also referred to in the article. Finally, the article provides a list of research centres involved in the studies of comics throughout the country and concludes that, although this area has experienced a noticeable expansion, there are still quite a few aims to reach, as far as education opportunities are concerned, such as the ongoing development of higher education study programmes, especially at master and doctoral levels.
\end{abstract}

\section{Keywords}

Comics; Communication; Research; School of Communication and Arts; ECA; University of São Paulo

\section{Autoria para correspondência}

Paulo Vitor Martins Albuquerque

paulovma@gmail.com 


\section{Como citar}

ALBUQUERQUE, Paulo Vitor Martins; MARINH, Maria Gabriela Silva Martins da Cunha; NERY, João Elias. Análise da pesquisa em HQs no Brasil: a contribuição da ECA-USP. Intexto, Porto Alegre, n. 52, e-104566, jan./dez. 2021. DOI: http://dx.doi.org/10.19132/1807-8583202152.103980

Recebido em 06/06/2020

Aceito em 13/07/2020 